\title{
Antibiotic Cefepime with Antacid, Metal Complexation studied by UV Spectrophotometrically in addition to Exploration of Antimicrobial Activity, In-Vitro Demonstration
}

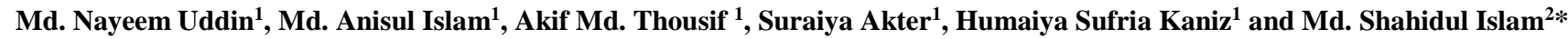 \\ ${ }^{1}$ Department of pharmacy, BGC Trust University, Bangladesh. \\ ${ }^{2}$ Department of pharmacy, University of Science and Technology Chittagong (USTC), Bangladesh.
}

Corresponding Author: Md. Shahidul Islam, Assistant Professor, Department of Pharmacy, University of Science \& Technology Chittagong (USTC), Bangladesh. Email: s_i_liton@yahoo.com

Received date: October 28, 2020; Accepted date: November 07, 2020; Published date: November 17,2020

Citation: Md. N. Uddin, Md. A. Islam, Akif Md. Thousif, Akter S., Humaiya S, Kaniz and Md. Shahidul Islam (2020) Antibiotic Cefepime with Antacid, Metal Complexation studied by UV Spectrophotometrically in addition to Exploration of Antimicrobial Activity, In-Vitro Demonstration, J. Pharmaceutics and Pharmacology Research 3(3); DOI: 10.31579/2693-7247/019

Copyright: (C) 2020, Shahidul Islam, This is an open access article distributed under the Creative Commons Attribution License, which permits unrestricted use, distribution, and reproduction in any medium, provided the original work is properly cited.

\begin{abstract}
As a fourth generation of cephalosporins, cefepime shows very superior activity in opposition to gram - negative organisms like Pseudomonas aeruginosa in addition to gram - positive organisms like Staphylococcus aureus. It is very functional in the lower respiratory tract infection reasoned by Influenza, Aureus, Pneumonia as well as Urinary tract infections caused by the E. Coli, skin in addition to skin structure infections reasoned by S. epidermidis in addition to intra-abdominal infection. The principal rationale of present follow a line of the exploration was to search in vitro interactions of the cefepime with key metal salt also antacid to settle on the bioavailability in view of antimicrobial movement of cefepime following drug metal communications at the pH7.4. Cefepime is one of the cephalosporin drugs so as to be exercised to treat numerous different sorts of infections originated by bacteria. Since the existence of compelling the ligand may influence bioavailability of metal in blood and tissues, for that reason with the intention of study the handy interaction of the cefepime with vital elements in attendance in the body. Cefepime has been related with $\mathrm{Zn}, \mathrm{Mg}$ as an in-vitro examination. Besides, the anti-microbial movement of drug along with the complexes was resolved. It has scrutinized that cefepime interrelates with metal and antacid on the $\mathrm{pH} 7.4$ by plotting various uv spectrophotometric methods. This examine authenticates that there was the interaction between cefepime and metal, antacid which was authenticated by job's plot technique furthermore by antimicrobial exploration. This was authenticated that region of inhibition of cefepime with Metal in addition to antacid condensed from $16 \mathrm{~mm}$ to $13 \mathrm{~mm}$ and $14 \mathrm{~mm}$ correspondingly. The typical cefepime disk also checked in opposition to Staphylococcus aureus.
\end{abstract}

Key Words: cefepime, spectrophotometry, antimicrobial action, complexation, job's plot

\section{Introduction}

Cefepime is the indicated for the respiratory tract infections, soft tissue infections, skin in addition to urinary tract infections as well as febrile neutropenia [1]. Cefepime is the chemically $1-[[(6 R, 7 R)-7-[2-(2$ - amino - 4 - thiazyl) glyoxylamido] -2 - carboxy -8 - oxo -5 thia -1 - azabicyclo [4.2.0] oct -2 - en -3 - yl] methyl ] - 1 - methyl pyrrolidinium chloride, $72-(\mathrm{Z})-(0$ - methyloxime $)$ monohydrochloride , monohydrate. This is the white to pale yellow powder extremely soluble in the water with molecular weight (MW) of 571.5 [2]. At this moment drug interface be capable of the simply be distinct as the interaction connecting a medicine in addition to additional substance with intention of the prevent medicine commencing the stage as expected. These correlations may happen by reason of be short of the knowledge regarding the principle ingredients associated in related substances [3].Two medicines are antagonistic at what time their interaction occurs a reduce in special effects of one or else both of medicines. The dissimilar responses of receptor to act of a medicine has effected in number of arrangements, which use expressions such as "partial agonist", "competitive agonist" etc. This is even expected that a lot of authors would mismanage any given arrangement [4] Commonly iron complexes were used in convey of oxygen in human blood as well as tissues. A mature at rest takes $250 \mathrm{ml}$ of uncontaminated oxygen for each minute, these oxygen conceded by metal complex convey system recognized heame, alloying oxygen to go away the blood at what time it arrives the tissue [5]. Antibiotic and metal interaction and successfully found there after interaction result. Also, the antimicrobial activity of drug and the metals complexes were determined. This has been seen that the antibiotic interacts along with metal at the $\mathrm{pH}$ 7.4. The different essential metal intricate of the many drugs has been synthesized in addition to characterized by the techniques like NMR, UV, atomic absorption, FT-IR as well as elemental analysis. Spectroscopic, IR Spectroscopic, disk diffusion method, Biological assay studies of complexes [6]. On the other hand in this interaction there uses metals complex which are interaction with drug into our body. And have been use there various type of bacteria for finding zone of inhibition. Some paper there uses methanol and ethanol for disk diffusion result clearly showing [7]. 


\section{Materials \& Methods}

\begin{tabular}{|c|l|l|}
\hline S. No & \multicolumn{1}{|c|}{ Name } & \multicolumn{1}{c|}{ Source } \\
\hline 1 & cefepime & Gift samples from Renata pharmaceuticals Ltd. \\
\hline 2 & Zinc Sulphate (Metal) & Merck ltd, Mumbai, India \\
\hline 3 & $\begin{array}{c}\text { Magnesium } \\
\text { Hydroxide(Antacid) }\end{array}$ & Merck ltd, Mumbai, India \\
\hline 4 & $\begin{array}{l}\text { Sodium di-hydrogen } \\
\text { phosphate }\end{array}$ & USTC, Foys lake, Chittagong, dept. of pharmacy \\
\hline 6 & $\begin{array}{l}\text { Disodium hydrogen } \\
\text { phosphate }\end{array}$ & USTC, Foys lake, Chittagong, dept. of pharmacy \\
\hline
\end{tabular}

Table 1. List of chemicals and reagents

\begin{tabular}{|l|l|l|}
\hline \multicolumn{1}{|c|}{ Name } & \multicolumn{1}{c|}{ Model } & \multicolumn{1}{c|}{ Source } \\
\hline pH Meter & $\mathrm{P}^{\mathrm{H}}-211$ & Hanna, Romania \\
\hline UV spectrophotometer & $\mathrm{T} 80$ & PG instrument Ltd, England \\
\hline Electronic Balance & AL-204 & Mettler toleddo, Switzerland \\
\hline Pipette & & Fischer scientific, Germany \\
\hline
\end{tabular}

Table 2. List of instruments \& equipment's

Cefepime stock solution 250 milliliter of $1 \times 10^{-2}$ Molar was ready by softening $1.386 \mathrm{gm}$ of cefepime solution in the 250 milliliter of the demineralized water (DMW) in a 250 milliliter volumetric flask. The reserve solution was thinned to desired potency by the buffer solution [8].

\section{Preparation of metal solutions:}

For the grounding of 0.01 Molar metal solution like zinc sulfate hepta hydrate ( exactly $0.28754 \mathrm{gm}$ ) was evaluated exactly in addition to initiated with the assist of the funnel in a $100 \mathrm{ml}$ volumetric flask, softened in DM water in addition to framework to the mark by the similar solvent. These prime solutions were additional diluted ten creases in the equivalent solvent along with the concluding solutions were $0.0001 \mathrm{M}$ concentration.

\section{Preparation of antacid solutions:}

For the preparation of $0.01 \mathrm{M}$ antacid solution, $\mathrm{Mg}(\mathrm{OH})_{2}(0.0740 \mathrm{gm})$ was evaluated accurately in addition to initiated with the facilitate of funnel in 100 milliliter volumetric flask, softened in the demineralized water furthermore construct up to mark by the equal solvent. These primary solutions were further diluted ten folds in the same solvent and the final solutions were $0.0001 \mathrm{M}$ concentration.

\section{Grounding of the buffer solutions:}

To get ready buffer solution 1.76 gram of the disodium hydrogen phosphate were softened in the demineralized water by 2.43 gtam of the solution dihydrogen phosphate in addition to $\mathrm{pH}$ was altered to 7.4 as well as volume was completed to 1000 milliliter with the equivalent solution.

\section{Grounding of the typical curve of the cefepime}

cefepime reserve solution at the $\mathrm{pH} 7.4$ in addition to concentration of the $1 \times 10^{-5}$ Molar was inserted in unlike concentrations to the 10 test tubes, to have subsequent concentrations like $9 \times 10^{-5}$ Molar, $8 \times 10^{-5}$ Molar, $7 \times 10^{-5}$ Molar, $6 \times 10^{-5}$ Molar, $5 \times 10^{-5}$ Molar, $4 \times 10^{-5}$ Molar, $3 \times 10^{-5}$ Molar, $2 \times 10^{-5}$ Molar, $1 \times 10^{-5}$ Molar. Now the solutions were suitably mixed. Then the absorbance values of solutions were established at $515 \mathrm{~nm}$ through UV spectrometer [9].

\section{Using Disc Diffusion Process:}

Solution of celebrated concentration $(3 \mu \mathrm{g} / \mathrm{ml})$ of trial samples are completed through dissolving measured quantity of the trials in calculated amount of solvents. Dried in addition to sterilized filter term paper discs (6 $\mathrm{mm}$ as a diameter) are subsequently impregnated with recognized amounts of trial substances by using micropipette . Discs holding the test substances are positioned on the nutrient agar media homogeneously seeded by the test organism, typical antibiotic discs along with blank discs were utilized as positive furthermore negative control. These plates now are kept at the low temperature like $4^{\circ} \mathrm{C}$ for the 24 hours to permit maximum diffusion. Throughout this time desiccated discs suck up water from surrounding medium furthermore the trial materials dissolve along with spread out of the trial disc. The diffusion happens according to physical law so as to controls diffusion of the molecules during agar gel. Consequently there was a gradual alter of trial substances concentrations in medium adjoining the disc [10].

\section{Results and Discussions}

From the subsequent Table 3, this can monitor to the absorbance of the cefepime enhances with the enhancing concentration in keeping with Beer Lambert's equation.

\begin{tabular}{|c|c|}
\hline Mx10 $^{-5}$ & Absorbance \\
\hline 1 & 0.573 \\
\hline 2 & 0.581 \\
\hline 3 & 0.595 \\
\hline 4 & 0.604 \\
\hline 5 & 0.617 \\
\hline 6 & 0.624 \\
\hline 7 & 0.631 \\
\hline 8 & 0.640 \\
\hline 9 & 0.645 \\
\hline
\end{tabular}

Table 3. Standard curve of cefepime 


\begin{tabular}{|c|c|}
\hline Wavelength & Absorbance \\
\hline 200 & 0.038 \\
\hline 240 & 0.040 \\
\hline 280 & 0.340 \\
\hline 320 & 0.180 \\
\hline 360 & 0.107 \\
\hline 400 & 0.030 \\
\hline 440 & 0.035 \\
\hline 480 & 0.066 \\
\hline 520 & 0.089 \\
\hline 560 & 0.096 \\
\hline 600 & 0.126 \\
\hline 640 & 0.137 \\
\hline
\end{tabular}

Table 4. Absorbance of cefepime at different wavelength

\begin{tabular}{|c|c|c|}
\hline Wavelength/nm & $\begin{array}{c}\text { Absorbance of } \\
\text { Cefepime }\end{array}$ & $\begin{array}{c}\text { Absorbance of Cefepime } \\
\text { with } \mathbf{M g}(\mathbf{O H})_{\mathbf{2}}\end{array}$ \\
\hline 200 & 0.038 & 0.544 \\
\hline 240 & 0.040 & 0.777 \\
\hline 280 & 0.340 & 0.663 \\
\hline 320 & 0.180 & 0.324 \\
\hline 360 & 0.107 & 0.183 \\
\hline 400 & 0.030 & 0.093 \\
\hline 440 & 0.035 & 0.136 \\
\hline 480 & 0.066 & 0.148 \\
\hline 520 & 0.089 & 0.170 \\
\hline 560 & 0.096 & 0.179 \\
\hline 600 & 0.126 & 0.190 \\
\hline 640 & 0.137 & 0.194 \\
\hline
\end{tabular}

Table 5. Spectral analysis of cefepime with $\mathrm{Mg}(\mathrm{OH}) 2$

\begin{tabular}{|c|c|c|c|c|c|}
\hline $\begin{array}{l}\text { Concentration } \\
\text { of cefepime } \\
\mathbf{M x 1 0}^{-5}\end{array}$ & $\begin{array}{l}\text { Absorbance } \\
\text { of cefepime } \\
\text { A }\end{array}$ & $\begin{array}{l}\text { Concentration } \\
\text { of } \mathrm{ZnSO}_{4} .7 \mathrm{H}_{2} \mathrm{O} \\
\mathrm{Mx10}^{-5}\end{array}$ & $\begin{array}{l}\text { Absorbance of } \\
\mathrm{ZnSO}_{4} .7 \mathrm{H}_{2} \mathrm{O} \\
\text { B }\end{array}$ & $\begin{array}{l}\text { Absorbance of } \\
\text { mixture } \\
\text { C }\end{array}$ & $\begin{array}{l}\text { Absorbance } \\
\text { difference } \\
D=(A+B)-C\end{array}$ \\
\hline 1 & 0.573 & 9 & 0.188 & 0.111 & 0.650 \\
\hline 2 & 0.581 & 8 & 0.187 & 0.109 & 0.659 \\
\hline 3 & 0.595 & 7 & 0.188 & 0.109 & 0.674 \\
\hline 4 & 0.604 & 6 & 0.189 & 0.112 & 0.681 \\
\hline 5 & 0.617 & 5 & 0.190 & 0.111 & 0.696 \\
\hline 6 & 0.624 & 4 & 0.193 & 0.128 & 0.689 \\
\hline 7 & 0.631 & 3 & 0.182 & 0.125 & 0.688 \\
\hline 8 & 0.640 & 2 & 0.180 & 0.136 & 0.684 \\
\hline 9 & 0.645 & 1 & 0.178 & 0.150 & 0.673 \\
\hline
\end{tabular}

Table 7. Values of job's plot of cefepime with $\mathrm{ZnSO} 4.7 \mathrm{H} 2 \mathrm{O}$

From the above we can observe that cefepime forms strong 1:1 complexes with zinc sulfate hepta hydrate which is indicated as inverted ' $\mathrm{V}$ ' shaped curve.

\begin{tabular}{|c|c|c|c|c|c|}
\hline $\begin{array}{l}\text { Concentration } \\
\text { of cefepime } \\
\mathbf{M x 1 0}^{-5}\end{array}$ & $\begin{array}{l}\text { Absorbance } \\
\text { of cefepime A }\end{array}$ & $\begin{array}{l}\text { Concentration } \\
\text { of } \mathbf{M g}(\mathbf{O H})_{2} \\
\mathbf{M x 1 0}\end{array}$ & $\begin{array}{l}\text { Absorbance } \\
\text { of } \mathbf{M g}(\mathbf{O H})_{2} \\
\mathbf{B}\end{array}$ & $\begin{array}{l}\text { Absorbance of } \\
\text { mixture } \\
\mathbf{C}\end{array}$ & $\begin{array}{l}\text { Absorbance } \\
\text { difference } \\
\mathbf{D =}=(\mathbf{A}+\mathbf{B})-\mathbf{C}\end{array}$ \\
\hline 1 & 0.573 & 9 & 0.091 & 0.115 & 0.549 \\
\hline 2 & 0.581 & 8 & 0.087 & 0.113 & 0.555 \\
\hline 3 & 0.595 & 7 & 0.094 & 0.119 & 0.570 \\
\hline 4 & 0.604 & 6 & 0.097 & 0.119 & 0.582 \\
\hline 5 & 0.617 & 5 & 0.104 & 0.121 & 0.600 \\
\hline 6 & 0.624 & 4 & 0.098 & 0.133 & 0.589 \\
\hline 7 & 0.631 & 3 & 0.093 & 0.137 & 0.587 \\
\hline 8 & 0.640 & 2 & 0.086 & 0.148 & 0.578 \\
\hline 9 & 0.645 & 1 & 0.084 & 0.163 & 0.566 \\
\hline
\end{tabular}

Table 8. Values of Job plot of cefepime and $\mathrm{Mg}(\mathrm{OH}) 2$ 
From the above we can observe that cefepime forms strong 1:1 complexes with $\mathrm{Mg}(\mathrm{OH})_{2}$ which is indicated as inverted ' $\mathrm{v}$ ' shaped curve.

\begin{tabular}{|c|c|c|}
\hline Cefepime & Cefepime with $\mathbf{Z n S O}_{\mathbf{4}} . \mathbf{7} \mathbf{H}_{\mathbf{2}} \mathbf{O}$ & Cefepime with $\mathbf{M g}(\mathbf{O H})_{\mathbf{2}}$ \\
\hline 0.573 & 0.188 & 0.091 \\
\hline 0.581 & 0.187 & 0.087 \\
\hline 0.595 & 0.188 & 0.094 \\
\hline 0.604 & 0.189 & 0.097 \\
\hline 0.617 & 0.190 & 0.104 \\
\hline 0.624 & 0.193 & 0.098 \\
\hline 0.631 & 0.182 & 0.093 \\
\hline 0.640 & 0.180 & 0.086 \\
\hline 0.645 & 0.178 & 0.084 \\
\hline
\end{tabular}

Table 9. Combined absorbance of drug with different metal \& antacid:

\section{Antimicrobial reading}

The antimicrobial effectiveness of the trial agents is calculated by their action to avoid the enlargement of microorganisms neighboring discs which provides clear precinct of inhibition. Later than incubation, the antimicrobial actions of the trial materials were concluded through measuring diameter of zones of the inhibition inside millimeter through a crystal clear $\mathrm{mm}$ scale. The trial samples were examined in opposition to Staphylococcus aureus. The typical cefepime disk also checked in opposition to staphylococcus aureus. The consequences of the antimicrobial action, calculated in view of diameter of the zone of the inhibition in the $\mathrm{mm}$ were demonstrated in table 10.

\begin{tabular}{|c|c|c|}
\hline Bacteria Used & Standard Disk (Zone of inhibition/mm) & Sample Disk (Zone of inhibition) \\
\hline Staphylococcus aureus & $16 \mathrm{~mm}$ & Cefepime $+\mathrm{ZnSO}_{4} .7 \mathrm{H}_{2} \mathrm{O} \quad 13 \mathrm{~mm}$ \\
\hline Staphylococcus aureus & $16 \mathrm{~mm}$ & Cefepime $+\mathrm{Mg}(\mathrm{OH})_{2}$ \\
& & $14 \mathrm{~mm}$ \\
\hline
\end{tabular}

Table 10. Diameter of zone of inhibition

Antimicrobial sensitivity testing of cefepime against Staphylococcus aureus after interacting with $\mathrm{ZnSO}_{4} .7 \mathrm{H}_{2} \mathrm{O}$ and $\mathrm{Mg}(\mathrm{OH})_{2}$ solution respectively.

Now it was proved that zone of the inhibition of the cefepime through Metal and antacid $\mathrm{Zn}, \mathrm{Mg}$ reduced from $16 \mathrm{~mm}$ to $14 \mathrm{~mm} \& 13 \mathrm{~mm}$ correspondingly due to the metal, antacid and drug interaction.

\section{Conclusion}

Though, there were some limitations in this research work like proper financial support from any side, active pure drug collection was not easy in Bangladesh. Eventually it has been overcome. The sophisticated spectrophotometric technique is easy, straight as well as worthwhile for the fortitude of drug. Commencing this spectral reading, this has been observed that cefepime provides a spiky peak at the $585 \mathrm{~nm}$. At what time Zinc Sulfate furthermore antacid solution, $\mathrm{Mg}(\mathrm{OH})_{2}$ combined with cefepime 1:1 ratio and the strength of peak alters extremely and absorption features are changed due to the interaction although the position of complex do not change. Then antimicrobial viewing of an mediator is crucial to find out its spectrum in opposition to various natures of the pathogenic microorganisms. The Job's plot have provided the molar percentage of the complexes of cefepime through Zinc Sulfate in addition to antacid solution like $\mathrm{Mg}(\mathrm{OH})_{2}$. At the $\mathrm{pH} 7.4$ cefepime structures tough 1:1 complexes through Zinc Sulfate in addition to antacid solution like $\operatorname{Mg}(\mathrm{OH})_{2}$ designated as ' $\wedge$ ' natured curves. These curves can indicate well-built kinetics of the complexation between cefepime by Zinc Sulfate along with antacid solution like magnesium hydroxide. The trial samples were checked in opposition to Staphylococcus aureus. The typical cefepime disk also checked in opposition to Staphylococcus aureus. It was examined that antimicrobial action of the cefepime reduces when it structures complexes through $\mathrm{ZnSO}_{4} .7 \mathrm{H}_{2} \mathrm{O}$ in addition to antacid solution like magnesium hydroxide. Thus, through antimicrobial examination it was proved that zone of the inhibition of the cefepime through Metal and antacid $\mathrm{Zn}, \mathrm{Mg}$ reduced from $16 \mathrm{~mm}$ to $13 \mathrm{~mm}$ \& $14 \mathrm{~mm}$ correspondingly.

\section{References}

1. H. Elkhaili, L. Linger, H. Monteil and F.Jehl, (1997). High performance liquid chromatographic assay for cefepime in serum, J. Chromatogr. B, 690,181-188

2. D. Breilh, C. Lavallee, A. Fratta, D. Ducint, P. Cony - Makhoul and M. C. Saux, (1999). Determination of cefepime and cefpirome in human serum by high - performance liquid chromatography using an ultrafiltration for antibiotics serum extraction, $J$. Chromatogr.B,734,121-127

3. F. J. J. Palacios, M. C. Mochon, J. C. J.Sanchez, M. A. B. Lopez and A. G.Perez, (2005) Validation of an HPLC method for determination of cefepime (a fourth -generation cephalosporin) determination in human serum, cerebrospinal fluid and urine pharmacokinetic profiles, Chromatographia,62,355 -361.

4. K. J. V. Lopez, D. F. Bertoluci, K. M.Vicente, A. M. Dell' Aquilla and S. R. C. J. Santos, (2007) Simultaneous determination of cefepime, vancomycin and imipenem in human plasma of burn patients by high-performance liquid chromatography, $J$. Chromatogr., 860 241-245.

5. R. Denooz and C. Charlier, (2008) Simultaneous determination of five $\beta$ - lactam antibiotics (cefepim, ceftazidim, cefuroxim, meropenem and piperacillin) in human plasma by high performance liquid chromatography with ultraviolet detection, ibid, 864 161-167.

6. S Koppisett V, Chandra N. (2011) Influence of Alcohol and Smoking on Drug Action: A Step for better utilization of drugs. Journal of Chemical and Pharmaceutical Research; 3(1) (0975-7384):242-248.

7. Chou TC. (2006) Theoretical basis, experimental design, and computerized simulation of synergism and antagonism in drug combination studies. Pharmacological reviews. Sep 1; 58(3):62181.

8. C.Sadowski D. (2012) Drug Interactions with Antacids Mechanisms and Clinical Significance. Springer international journal. Volume 11(issue: 6): pp 395-407. 
9. Chafle D. M. (2013) "Development and validation of spectrophotometric method for the estimation of cefepime in bulk and dosage form".Der Pharma Chemica, 5 (2):127-132
10. Billov S, Kizek R, Jelen F, Novotn P, (2003) Squarewavevoltammetric determination of cefoperazone in abacterial culture, pharmaceutical drug, milk, and urine. Analytical and Bioanalytical Chemistry, 377(2): 362-369.
This work is licensed under Creative Commons Attribution 4.0 License

\section{To Submit Your Article Click Here: Submit Manuscript}

DOI: $10.31579 / 2693-7247 / 019$
Ready to submit your research? Choose Auctores and benefit from:

* fast, convenient online submission

* rigorous peer review by experienced research in your field

* rapid publication on acceptance

* authors retain copyrights

* unique DOI for all articles

* immediate, unrestricted online access

At Auctores, research is always in progress.

Learn more www.auctoresonline.org/journals/pharmaceutics-andpharmacology-research 